\title{
Lead in drinking water: a response from the Atlantic PATH study
}

\author{
Ellen Sweeney*, Zhijie M. Yu*, Louise Parker*† and Trevor J.B. Dummer \\ *Atlantic PATH, Population Cancer Research Program, Dalhousie University, Halifax, Nova Scotia, Canada. \\ ${ }^{\dagger}$ Atlantic PATH, Population Cancer Research Program, Department of Pediatrics, Dalhousie University, Halifax, Nova Scotia, Canada. \\ ॠCentre of Excellence in Cancer Prevention, School of Population and Public Health, University of British Columbia, Vancouver, \\ British Columbia, Canada.
}

\begin{abstract}
Exposure to lead through drinking water is an issue of increasing concern, particularly with recent high-profile cases of lead-contaminated water. The maximum acceptable concentration level for drinking water in Canada is $10 \mu \mathrm{g} / \mathrm{L}$, whereas the current blood intervention level is $10 \mu \mathrm{g} / \mathrm{dL}$. The health effects related to lead exposure are well established and there is evidence that blood lead levels as low as $<5 \mu \mathrm{g} / \mathrm{dL}$ are associated with adverse health effects in both children and adults. We analyzed water and toenail samples for lead concentrations from the Atlantic Partnership for Tomorrow's Health (Atlantic PATH) project, a cohort of the general population in Nova Scotia. Approximately $46 \%$ of Nova Scotia residents use well water as their primary source of drinking water. Water from dug wells had higher lead concentrations compared to drilled wells, and the lowest lead levels were found in water from municipal supplies. Although the majority of the lead levels in the drinking water provided by Atlantic PATH participants were below the Canadian maximum acceptable concentration level, there were outliers, particularly among unregulated private well water sources. Given the health effects that are linked to low-level exposures, any exposure to lead in primary water sources remains a concern.
\end{abstract}

Key words: drinking water, lead, exposure

\section{Introduction}

Exposure to lead through drinking water is an issue of increasing concern, with significant attention in the mainstream media and related academic research. Most recently, a change in the water source from Lake Huron to the Flint River in Flint, Michigan resulted in the supply of more corrosive water, which occurred alongside a lack of adequate corrosion control measures (Bellinger, 2016). The failure to apply adequate corrosion control lasted for more than 18 months and allowed metals, including lead, to dissolve in the drinking water. Increases in both drinking water lead levels and human blood lead levels were reported. Of the residential water samples tested, more than $40 \%$ of the samples were $>5 \mu \mathrm{g} / \mathrm{L}$ ( $5 \mathrm{ppb}$ ), with the 90 th percentile at $25 \mu \mathrm{g} / \mathrm{L}$, and other samples ranging between 100 and $1,000 \mu \mathrm{g} / \mathrm{L}$ (Parks and Mantha, 2016; Edwards et al., 2015). The blood lead levels of children were examined after the change in water source, and there was an increase in the incidence of blood lead levels $>5 \mu \mathrm{g} / \mathrm{dL}$ from $2.4 \%$ to $4.9 \%$, with a $6.6 \%$ increase in neighbourhoods that had the highest water lead levels. No other alternative source of increased lead exposure was identified during this time period (Hanna-Attisha et al., 2016).

Corresponding author: Ellen Sweeney (email: ellen.sweeney@dal.ca)
The health effects related to lead exposure are well established and there is evidence that blood lead levels of as low as $<5 \mu \mathrm{g} / \mathrm{dL}$ are associated with adverse health effects in both children and adults (National Toxicology Program, 2012). Low-level effects of lead are associated with neurodevelopmental, neurodegenerative, cardiovascular, renal, reproductive, and developmental impacts. An increase of $1 \mu \mathrm{g} / \mathrm{dL}$ of lead levels in blood is associated with a deficit of approximately one IQ point (Health Canada, 2013a, 2013b). Fetuses and infants have an increased risk as they experience greater susceptibility to the toxic effects of lead exposure, which can result in a decrease in cognitive performance and an increase in attention-related behavioural issues (National Toxicology Program, 2012). Lead has also been classified as possibly carcinogenic to humans (2B carcinogen) (International Agency for Research on Cancer, 2016).

The United States Environmental Protection Agency (EPA) estimates that drinking water can contribute $20 \%$ or more of a person's total exposure to lead, and up to $40 \%-60 \%$ in infants with a formula diet. As lead is persistent in the body, is bioaccumulative and has health effects at very low levels, the EPA set the maximum contaminant level goal for lead in drinking water at zero (United States Environmental Protection Agency, 2016). Prior to 2012, the blood lead level of concern for 
children was $10 \mu \mathrm{g} / \mathrm{dL}$. However, the Centers for Disease Control and Prevention no longer use the term "level of concern," and now use a reference blood level of $5 \mu \mathrm{g} / \mathrm{dL}$ (Centers for Disease Control and Prevention, 2012, 2016).

The maximum acceptable concentration (MAC) for lead in drinking water in Canada is $10 \mu \mathrm{g} / \mathrm{L}(10 \mathrm{ppb})$, while the current blood intervention level remains at $10 \mu \mathrm{g} / \mathrm{dL}$ (Health Canada, 1992, 2013a). Although lead is detected in the blood levels of all Canadians, it has decreased in the general population from a mean of $4.8 \mu \mathrm{g} / \mathrm{dL}$ in 1979 (Health Canada, 2013a). The most recent Canadian Health Measures Survey measured lead as part of its human biomonitoring efforts. It found that the geometric mean of the whole blood concentration among participants aged 6-79 years was $1.1 \mu \mathrm{g} / \mathrm{dL}$ (95\% CI: 1.0-1.2). The median at the 10th percentile was $0.49 \mu \mathrm{g} / \mathrm{dL}(95 \%$ CI: $0.46-0.52), 1.0 \mu \mathrm{g} / \mathrm{dL}$ (95\% CI: 0.96-1.1) at the 50th percentile, $2.4 \mu \mathrm{g} / \mathrm{dL}$ (95\% CI: $2.3-2.5$ ) at the 90th percentile, and $3.2 \mu \mathrm{g} / \mathrm{dL}$ (95\% CI: 2.9-3.4) at the 95th percentile (Health Canada, 2015). Health Canada (2013a) recognizes the health effects can occur as a result of low-level exposure to lead, and has concluded that "additional measures to further reduce exposures of Canadians to lead, with a particular focus on vulnerable populations, are warranted." The federal risk management strategy includes a review of the drinking water guidelines, including exposure to lead and sampling and monitoring strategies (Health Canada, 2013a).

The Atlantic Partnership for Tomorrow's Health (Atlantic PATH) study sought to contribute to discussions about the recent concerns related to drinking water lead exposure. The objectives of this paper are to $(i)$ analyze drinking water and toenail samples from the Atlantic PATH study participants for lead concentrations, (ii) evaluate the potential for toenail clipping samples to be used as a noninvasive approach for measuring lead exposure in humans, and (iii) determine whether the various drinking water sources (municipal, drilled wells, dug wells) are mediators of differing levels of lead exposure.

\section{Methods}

Atlantic PATH is a longitudinal cohort study that is part of the Canadian Partnership for Tomorrow Project, and includes over 30,000 adult participants aged 35-69 years from Nova Scotia, New Brunswick, Prince Edward Island, and Newfoundland and Labrador (Borugian et al., 2010; Yu et al., 2014a). The data collected from participants at baseline recruitment included socio-demographic, health and lifestyle information; physical measures; and blood, urine, saliva, and toenail samples. Well water samples in Nova Scotia were also collected as part of a sub-study focused on arsenic and heavy metal exposures (Yu et al., 2014b). It should be noted that Atlantic PATH's protocol for testing water instructed participants to run the tap for 10 minutes to flush the system. However, this technique may artificially lower lead levels compared to water that has not been flushed (Ngueta et al., 2016). Ethical approval was received by the relevant research ethics boards and all participants provided written informed consent.

For this paper, water samples $(\mathrm{n}=2,750)$ and toenail samples $(\mathrm{n}=2,345)$ were selected based on the participants' residing in Nova Scotia; exclusion criteria included samples from an unknown water source. Toenail and water samples were analyzed for lead and other elements using ICP-MS, described previously (Yu et al., 2014b). We utilized the Fisher's exact statistical test to examine the differences in the prevalence of high water lead among water samples with different characteristics. The relationship between lead concentrations in water and toenails were analyzed by using linear regression with adjustment for age, sex, ethnicity, education, smoking, and alcohol use. Differences in lead concentrations of toenail clipping samples across water source were detected with general linear models. Statistical significance was defined as $P<0.05$. All $P$ values were two-sided. Data management and analyses were performed with SAS statistical package version 9.4 (SAS Institute, Cary, North Carolina).

\section{Results}

Approximately $46 \%$ of the population of Nova Scotia uses well water as their primary source of water (Nova Scotia Department of Environment and Labour, 2006). The majority of the water samples collected from Atlantic PATH participants were obtained from the primary drinking water source of the household. The sources of the water samples collected from Atlantic PATH participants included 26\% municipal water $(\mathrm{n}=709), 53 \%$ drilled wells $(\mathrm{n}=1,454), 18 \%$ dug wells $(\mathrm{n}=503)$, and $3 \%$ other/unknown water sources $(\mathrm{n}=84)$. The geometric mean for lead concentrations in all drinking water samples was $0.35 \mu \mathrm{g} / \mathrm{L}$ (95\% CI, 0.32, 0.37), see Table 1 .

Among all water samples, 2.2\% $(\mathrm{n}=59)$ had lead levels in excess of the MAC $(>10 \mu \mathrm{g} / \mathrm{L})$, and these were predominantly from well water sources (Table 1). Water from dug wells had higher lead concentrations compared to drilled wells, and the lowest lead levels were found in water from municipal supplies.

Unlike for blood and drinking water, there is no guideline reference value for lead in toenails. However, while they have not yet been validated, toenails have the potential to be used as a biomarker for chronic lead exposure. The mean concentration for lead in the Atlantic PATH toenail samples $(\mathrm{n}=2,345)$ was $0.35 \mu \mathrm{g} / \mathrm{g}(95 \% \mathrm{CI}, 0.32,0.39)$, and the geometric mean was $0.15 \mu \mathrm{g} / \mathrm{g}(95 \% \mathrm{CI}, 0.14,0.16)$ (Table 2). In general, compared with males and participants in the younger age group, females and those in the older age group had significantly lower lead concentrations in toenails, respectively (all $P<0.001$ ). The geometric mean for females $(\mathrm{n}=1,671)$ was $0.14 \mu \mathrm{g} / \mathrm{g}$ (95\% CI, 0.13, 0.15), with $0.16 \mu \mathrm{g} / \mathrm{g}$ (95\% CI, 0.14, 0.17) among females aged 35-49 years and $0.13 \mu \mathrm{g} / \mathrm{g}$ (95\% CI, 0.12, 0.14 ) among females aged 50-69 years. Male participants ( $\mathrm{n}=$ 674 ) had higher levels of lead in toenails with a geometric mean of $0.19 \mu \mathrm{g} / \mathrm{g}$ (95\% CI, 0.17, 0.21), with $0.23 \mu \mathrm{g} / \mathrm{g}$ (95\% CI, $0.19,0.27)$ among males aged $35-49$ years, and $0.18 \mu \mathrm{g} / \mathrm{g}(95 \%$ CI, 0.16, 0.20) among males aged 50-69 years. The differences between these groups may be due to variations in cumulative lead exposures from different sources, such as drinking water, diet, smoking, and occupational exposures (Richter et al., 2013) that were not controlled for in the unadjusted analysis. 
Table 1. Differences in prevalent high water $\mathrm{Pb}(\geq 10 \mu \mathrm{g} / \mathrm{L})$ by characteristics

\begin{tabular}{|l|c|c|c|}
\hline Characteristics & No. & $\%$ & $P^{\mathbf{a}}$ \\
\hline Main home water & & & 0.22 \\
\hline Yes & $54 / 2,612$ & 2.1 & \\
\hline No & $5 / 138$ & 3.6 & \\
\hline Well water & & & 0.001 \\
\hline Yes & $54 / 2,040$ & 2.7 & \\
\hline No & $5 / 710$ & 0.7 & \\
\hline Water source & & & $<0.001$ \\
\hline Municipal treated water & $5 / 709$ & 0.7 & \\
\hline Drilled well & $26 / 1,454$ & 1.8 & \\
\hline Dug well & $22 / 503$ & 4.4 & \\
\hline Other/unknown & $6 / 84$ & 7.1 & \\
\hline
\end{tabular}

${ }^{a} P$ values were derived using the Fisher's exact test.

For every $1 \%$ increase of lead in water, there was a $0.1 \%$ increase of lead in toenails $(P<0.001)$. In the multivariable model controlling for important nondrinking water lead exposures, including smoking, diet, and occupational exposures, the geometric mean for lead in toenails with exposure to municipal treated water was $0.11 \mu \mathrm{g} / \mathrm{g}$ (95\% CI, 0.08, 0.15), see Table 3. Lead levels in toenail samples from those with a drilled well water source were slightly higher (geometric mean of $0.13 \mu \mathrm{g} / \mathrm{g}, 95 \% \mathrm{CI}, 0.10,0.18$ ). The highest levels of lead exposure were evident in the participants sourcing water from a dug well, geometric mean of $0.20 \mu \mathrm{g} / \mathrm{g}$ (95\% CI, 0.14, 0.28).

\section{Discussion}

While most studies on lead in drinking water concentrate on specific populations or occupational groups, the Atlantic PATH project focused on a cohort of Nova Scotians who were recruited from the general population. This study included both water and toenail samples, which provides a unique perspective on lead exposure among the general population, many of whom source drinking water from a private well. The use of toenails as an indicator of environmental exposure to lead may be of particular interest to those working in community monitoring and public health. Toenail clippings are a highly stable source for measuring the body burden of a range of elements, including lead, and they are easily collected, maintained, and transported. The collection of toenails involves a noninvasive process compared to blood samples, which may result in a higher rate of participation from the public.

There was significant variation in toenail lead levels by drinking water source, with the highest toenail lead in participants using dug wells, after adjustment for other factors that may affect lead exposure. Dug wells also had the highest levels of lead in drinking water. Although the majority of the lead levels in the drinking water provided by Atlantic PATH participants were below the Canadian MAC, there were outliers, particularly among unregulated private well water sources. Unlike private well water sources, municipal water suppliers are required to implement corrosion control plans to limit leaching of contaminants, such as lead from pipes into the water. Water from dug wells tends to rely upon surficial groundwater, which has lower $\mathrm{pH}$ and higher corrosivity levels compared to

Table 2. Lead in toenail samples

\begin{tabular}{|l|c|c|c|}
\hline & All & Males & Females \\
\hline Pb in toenail samples $(\boldsymbol{\mu g} / \mathbf{g})$ & $\mathbf{n}=\mathbf{2 , 3 4 5}$ & $\mathbf{n}=\mathbf{6 7 4}$ & $\mathbf{1 , 6 7 1}$ \\
\hline Mean $(95 \% \mathrm{CI})$ & $0.35(0.32,0.39)$ & $0.46(0.38,0.55)$ & $0.31(0.27,0.35)$ \\
\hline GM $(95 \% \mathrm{CI})$ & $0.15(0.14,0.16)$ & $0.19(0.17,0.21)$ & $0.14(0.13,0.15)$ \\
\hline Median $(\mathrm{IQR})$ & $0.14(0.07,0.29)$ & $0.17(0.09,0.38)$ & $0.13(0.07,0.27)$ \\
\hline $\mathbf{3 5 - 4 9}$ years & $\mathbf{n}=\mathbf{6 3 9}$ & $\mathbf{n}=\mathbf{1 5 5}$ & $\mathbf{n}=\mathbf{4 8 4}$ \\
\hline Mean $(95 \% \mathrm{CI})$ & $0.38(0.31,0.44)$ & $0.51(0.33,0.68)$ & $0.34(0.27,0.40)$ \\
\hline GM $(95 \% \mathrm{CI})$ & $0.17(0.16,0.19)$ & $0.23(0.19,0.27)$ & $0.16(0.14,0.17)$ \\
\hline Median $(\mathrm{IQR})$ & $0.16(0.08,0.28)$ & $0.21(0.12,0.48)$ & $0.15(0.08,0.32)$ \\
\hline $\mathbf{5 0 - 6 9}$ years & $\mathbf{n}=\mathbf{1 , 7 0 6}$ & $\mathbf{n}=\mathbf{5 1 9}$ & $\mathbf{n}=\mathbf{1 , 1 8 7}$ \\
\hline Mean $(95 \% \mathrm{CI})$ & $0.35(0.30,0.39)$ & $0.45(0.35,0.55)$ & $0.30(0.26,0.34)$ \\
\hline GM $(95 \% \mathrm{CI})$ & $0.144(0.136,0.153)$ & $0.18(0.16,0.20)$ & $0.13(0.12,0.14)$ \\
\hline Median $(\mathrm{IQR})$ & $0.14(0.07,0.28)$ & $0.16(0.08,0.35)$ & $0.12(0.06,0.26)$ \\
\hline
\end{tabular}

Note: CI, confidence interval; GM, geometric mean; IQR, inter-quartile range. 
Table 3. Lead concentration in toenail clipping samples by water source among participants with both water and toenail clipping samples $(n=1,393)$

\begin{tabular}{|c|c|c|}
\hline & \multicolumn{2}{|c|}{$\begin{array}{l}\text { Lead in toenail clippings }(\mu \mathrm{g} / \mathrm{g}) \text {, } \\
\text { GM }(95 \% \mathrm{CI})\end{array}$} \\
\hline Water sources & Simple model $^{\mathbf{a}}$ & $\begin{array}{c}\text { Multivariable } \\
\text { model }^{\text {b }}\end{array}$ \\
\hline $\begin{array}{l}\text { Municipal } \\
\text { treated water }\end{array}$ & $0.13(0.11,0.14)$ & $0.11(0.08,0.15)$ \\
\hline Drilled well & $0.15(0.14,0.16)$ & $0.13(0.10,0.18)$ \\
\hline Dug well & $0.23(0.20,0.26)$ & $0.20(0.14,0.28)$ \\
\hline Other/unknown & $0.14(0.10,0.19)$ & $0.12(0.08,0.19)$ \\
\hline Overall $P$ value & $<0.001$ & $<0.001$ \\
\hline
\end{tabular}

Note: GM, geometric mean; CI, confidence interval.

${ }^{a}$ Adjusted for age and sex.

${ }^{b}$ Adjusted for age, sex, ethnicity, education, smoking, and alcohol use.

bedrock aquifers that drilled wells draw upon. In this study, we were unable to determine if the lead exposure is occurring as a result of untreated water itself or lead leaching from the pipes as a result of corrosive water.

Given the health effects that are linked to low-level exposures, any exposure to lead in water sources remains concerning. While much of the focus of lead exposure is related to children, there is also evidence linking the cumulative exposure of lead in older adults to cognitive decline (Weuve et al., 2009). Given the aging population in Nova Scotia, this adds to the concerns about lead exposure via drinking water. Furthermore, unlike municipal water sources, private wells are essentially unregulated and therefore testing and treatment is the responsibility of the homeowner. Under such an approach to environmental public health, the onus is placed on private citizens to test their well water to ensure water safety. There is an opportunity for community-based public health efforts to develop knowledge translation campaigns for well water users that provide clear and informative outreach and education efforts. For instance, people with dug wells could be targeted by specific efforts describing the possibility of being exposed to higher levels of lead as a result of their water supply, as well as detailed information about potential remediation strategies. In Canada, residents who rely on well water for their primary drinking source are encouraged to regularly test their water for lead and other contaminants, and to consider the appropriate treatment options to reduce their exposure levels if necessary, such as filtration and reverse osmosis (Nova Scotia Environment, 2008).

\section{Acknowledgements}

The authors would like to acknowledge Dr. John Murimboh, Acadia University, for analysis of drinking water and toenail samples. Production of this study has been made possible through financial support from the Canadian Partnership Against Cancer and Health Canada, as well as through support from a grant from the Canadian Cancer Society (grant
\#19989). The views expressed herein represent the views of the authors and do not necessarily represent the views of Health Canada.

\section{References}

Bellinger, D. 2016. Lead contamination in Flint - An abject failure to protect public health. N. Engl. J. Med. 374(12): 1101-1103. doi: 10.1056/NEJMp1601013

Borugian, M. J., Robson, P., Fortier, I., Parker, L., McLaughlin, J., Knoppers, B. M., et al. 2010. The Canadian Partnership for Tomorrow Project: Building a pan-Canadian research platform for disease prevention. Can. Med. Assoc. J. 182: 1197-1201. doi: 10.1503/cmaj.091540

Centers for Disease Control and Prevention (CDC). 2012. CDC Response to Advisory Committee on childhood lead poisoning prevention recommendations in low level lead exposure harms children: A renewed call for primary prevention. Atlanta, GA: Centers for Disease Control and Prevention.

Centers for Disease Control and Prevention (CDC). 2016. Standard surveillance definitions and classifications. Available at: http://www.cdc.gov/nceh/lead/data/definitions.htm [accessed 19 April 2016].

Edwards, M., Falkinham, J., and Pruden, A. 2015. Synergistic impacts of corrosive water and interrupted corrosion control on chemical/ microbiological water quality. Flint, MI: National Science Foundation. Grant abstract. Available at: http://www.nsf.gov/awardsearch/showAward?AWD_ID=1556258\&HistoricalAwards=false [accessed 15 April 2016].

Hanna-Attisha, M., LaChance, J., Sadler, R. C., and Champney Schnepp, A. 2016. Elevated blood lead levels in children associated with the flint drinking water crisis: A spatial analysis of risk and public health response. Am. J. Public Health Res. 106(2): 283-290. doi: 10.2105/AJPH.2015.303003

Health Canada. 1992. Guidelines for Canadian drinking water quality: Guideline technical document - Lead. Available at: http:// healthycanadians.gc.ca/publications/healthy-living-vie-saine/waterlead-plomb-eau/index-eng.php [cited 2 September 2016].

Health Canada. 2013a. Risk management strategy for lead. Ottawa, ON: Health Canada.

Health Canada. 2013b. Final human health state of the science report on lead. Ottawa, ON: Health Canada.

Health Canada. 2015. Third report on human biomonitoring of environmental chemicals in Canada. Available at: http://www.hcsc.gc.ca/ewh-semt/pubs/contaminants/chms-ecms-cycle3/index-eng. php\#s10d [accessed 15 April 2016].

International Agency for Research on Cancer (IARC). 2016. IARC monographs on the evaluation of carcinogenic risk to humans. Agents Classified by the IARC Monographs, Volumes 1112. Available at: http://monographs.iarc.fr/ENG/Classification/ ClassificationsAlphaOrder.pdf [accessed 20 April 2016].

National Toxicology Program (NTP). 2012. NTP monograph: Health effects of low-level lead. National Institute of Environmental Health Sciences, National Institutes of Health, U.S. Department of Health and Human Services. Research Triangle Park, NC: National Toxicology Program.

Ngueta, G., Belkacem, A., Tardif, R., St-Laurent, J., and Levallois, P. 2016. Use of a cumulative exposure index to estimate the impact of 
tap water lead concentration on blood lead levels in 1- to 5-year-old children (Montréal, Canada). Environ. Health Perspect. 124(3): 388-395.

Nova Scotia Department of Environment and Labour. 2006. A drinking water strategy for Nova Scotia: A comprehensive approach to the management of drinking water. Halifax, NS: Nova Scotia Department of Environment and Labour.

Nova Scotia Environment. 2008. The drop on water: Lead. Available at: https://www.novascotia.ca/nse/water/docs/droponwaterFAQ Lead.pdf [accessed 25 May 2016].

Parks, J., and Mantha, A. 2016. Lead testing results for water sampled by residents. Flint Water Study, Virginia Tech University. Available at: http://flintwaterstudy.org/information-for-flint-residents/ results-for-citizen-testing-for-lead-300-kits/ [accessed 18 April 2016].

Richter, P. A., Bishop, E. E., Wang, J., and Kaufmann, R. 2013. Trends in tobacco smoke exposure and blood lead levels among youths and adults in the United States: The National Health and Nutrition Examination Survey, 1999-2008. Prev. Chronic. Dis. 10: E213. doi: $10.5888 / \operatorname{pcd} 10.130056$
United States Environmental Protection Agency. 2016. Basic information about lead in drinking water. Available at: https://www. epa.gov/your-drinking-water/basic-information-about-lead-drinkingwater [accessed 15 April 2016].

Weuve, J., Korrick, S. A., Weisskopf, M. A., Ryan, L. M., Schwartz, J., Nie, H., et al. 2009. Cumulative exposure to lead in relation to cognitive function in older women. Environ Health Perspect. 117 (4): 574-580. doi: 10.1289/ehp.11846

Yu, Z. M., Parker, L., and Dummer, T. J. B. 2014a. Depressive symptoms, diet quality, physical activity, and body composition among populations in Nova Scotia, Canada: Report from the Atlantic Partnership for Tomorrow's Health. Prev. Med. 61: 106113. doi: $10.1016 /$ j.ypmed.2013.12.022

Yu, Z. M., Dummer, T. J. B., Adams, A., Murimboh, J. D., and Parker, L. 2014b. Relationship between drinking water and toenail arsenic concentrations among a cohort of Nova Scotians. J. Expo. Sci. Environ. Epidemiol. 24: 135-144. doi: 10.1038/jes.2013.88 